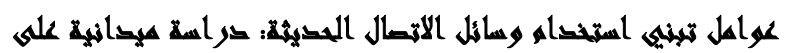

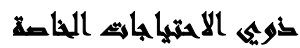

المقدمة:

شهـد العالم تغيرات جذريـة لعبت فيها المعلومـات دوراً أكبر مما سبق

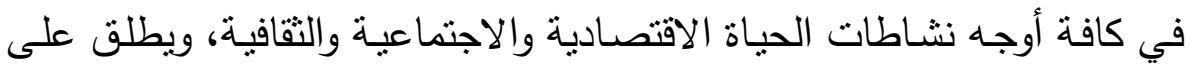
المجتمع الجديد اسم "مجتمع المعلومات" الذي يقوم على مبادئ أساسية منها

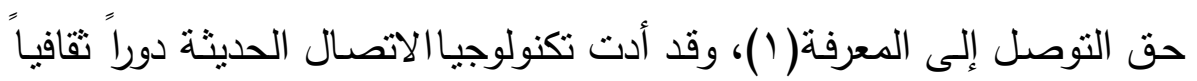

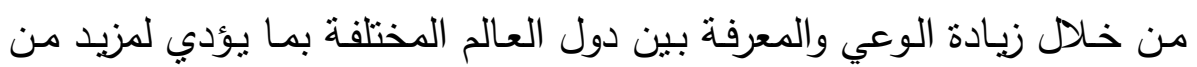

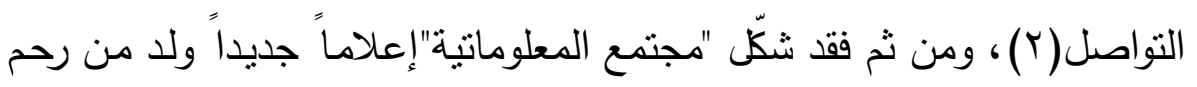

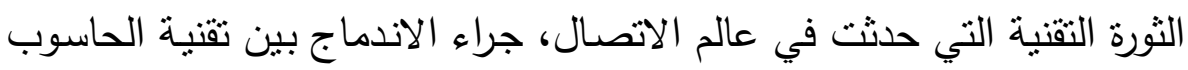

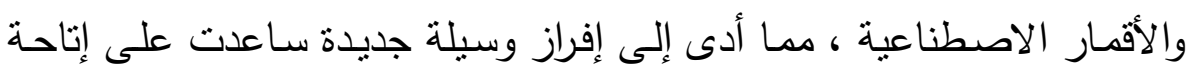

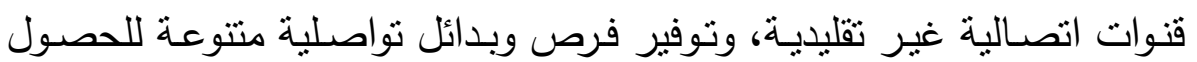

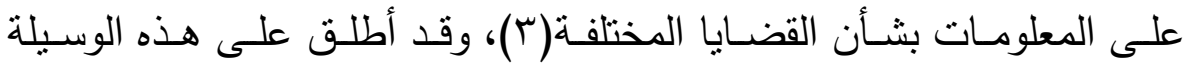

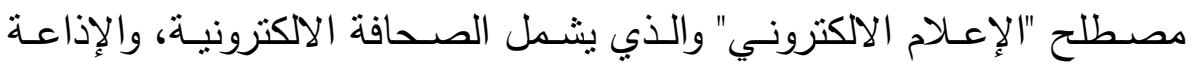

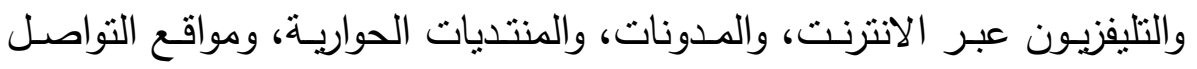

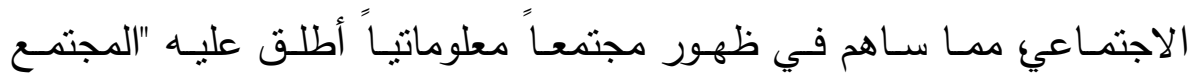

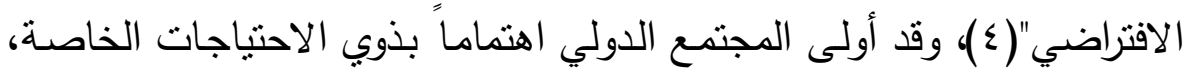

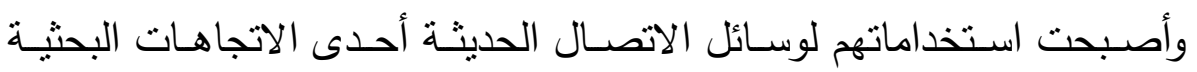

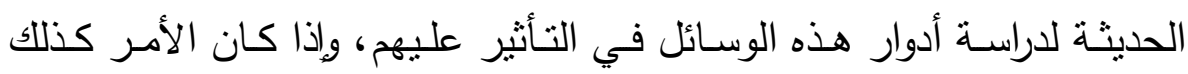

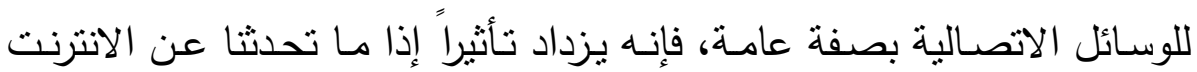

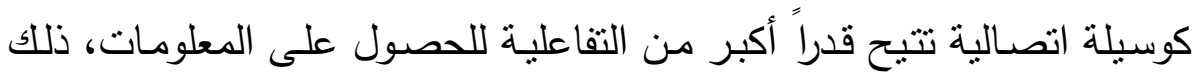

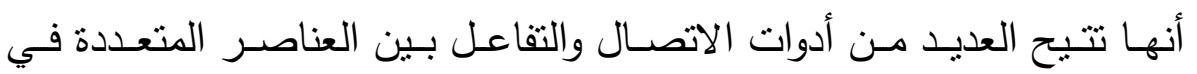

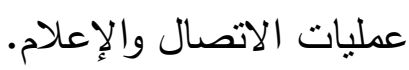




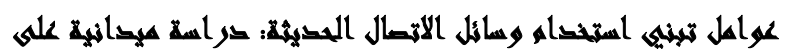

الارراسات السابقة:

دراسـة روبين وآخرون(0) بعنوان "ثـرح استخدام الثنبكة مـن خـلد نموذج قبول التكنولوجيا"، وسعت الدراسة إلى التعرف على العوامل المؤثرة في

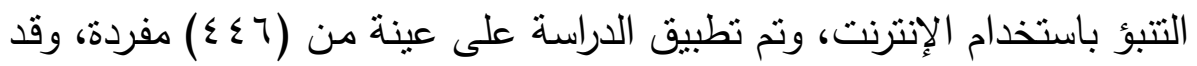

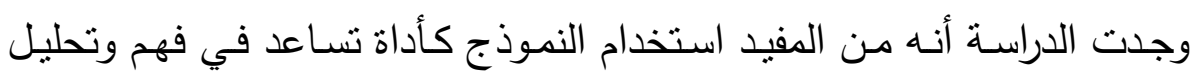

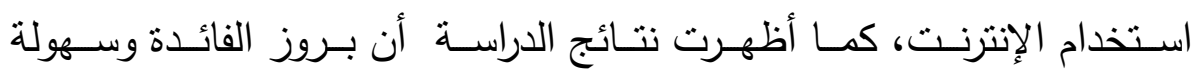
الاستخدام كعوامل مؤثرة في في الاستخدام.

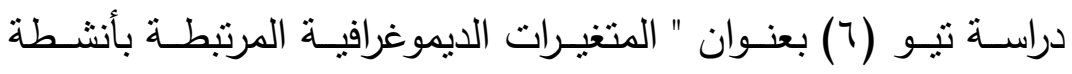

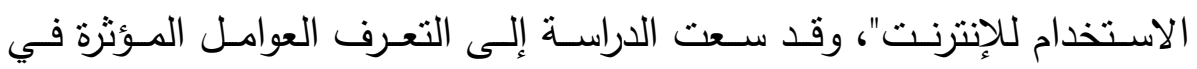

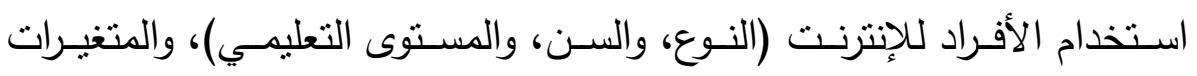

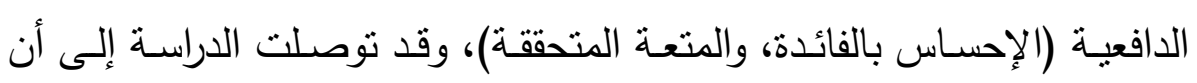

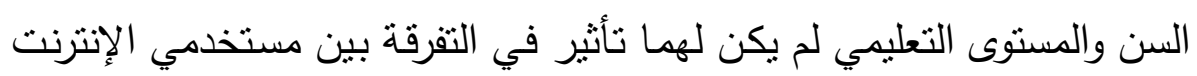
في أنشطه التسوق عبر الإنترنت.

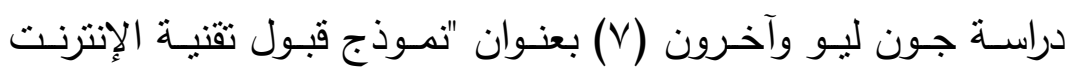
اللاسلكي"، وسعت الدراسة إلى الكثف على العوامل المؤثرة في قبول الإنترنت

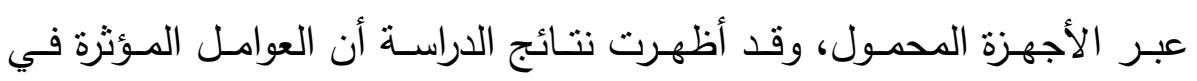

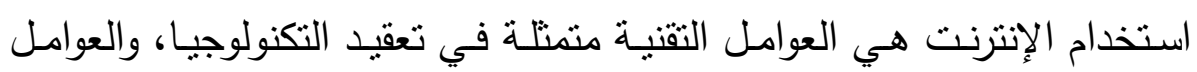

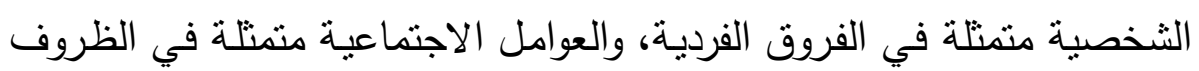
الميسرة والتأثير الاجتماعي ودرجة النقة.

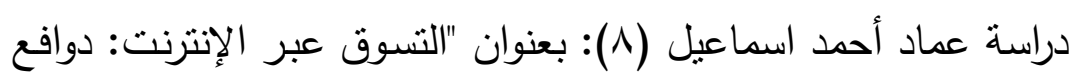

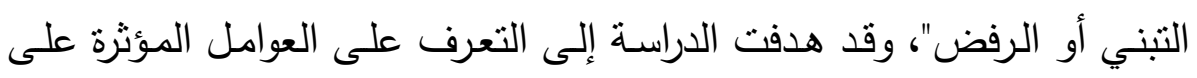




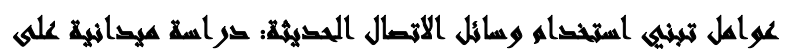

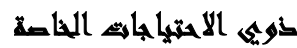

التسـوق عبر الإنترنـت والتعرف على الخصـائص الديموجرافيـة للمتبنين، وقد أظهرت الدراسـة وجود فروق بين المتبنين وغير المتبنين للتسوق عبر الإنترنت فيما في (النوع، والمستوى التعليمي، ومتوسط دخل الأسرة)، وعدم وجود فروق في الخصائص الديموجرافية بين المتبنين وغير المتبنين للتسوق عبر الإنترنت في خصائص (السن، البيئة الاجتماعية أي الإمارة التابع لها).

مشكلة الدراسة:

نظـراً لأهميـة دراسـة دور الإنترنـت كوسـيلة اتصـال حديثـة وكمجتمع

افتراضي يمكن من خلاله التواصل وتبادل المعلومات والمعارف، تتضـح الحاجة إلى دراسـة أنمـاط استخدامات الفئات الخاصـة للإنترنتـ، والعوامل المؤثرة في هذا الاستخدام، ومن هنا يمكن تحديد المشكلة البحثية في دراسة:

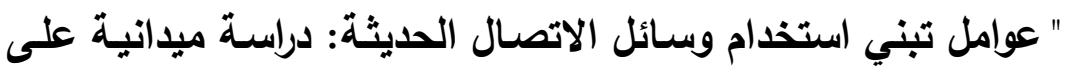

ذوي الاحتياجات الخاصة". أهداف الدراسة:

- التعرف على الفروق بين ذوي الاحتياجات الخاصـة في استخدامهم للإنترنت تبعاً للعوامل الديموجرافية. - التعرف على العوامل (المتعلقة بالمستخدم، المتعلقة بالوسيلة الاتصالية) التي تؤئز على استخدام أفراد ذوي الاحتياجات الخاصة للإنترنت.

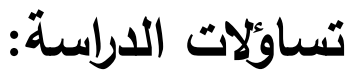

ا - ما كثافة تعرض أفراد ذوي الاحتياجات الخاصة للمواقع الإلكترونية؟ Y- ما تأثير استخدام الإنترنت على الوسائل الأخرى؟ 


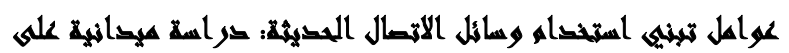

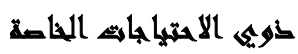

r- ما المضامين الالكترونية المفضلة لدى ذوي الاحتياجات الخاصة؟

ع - ما أنماط استخدام ذوي الاحتياجات الخاصة للمضامين الإكترونية ؟

فروض الاراسة:

ا - توجد فروق ذات دلالـة إحصـائية بين أفراد ذوي الاحتياجات الخاصـة في كثافـة اسـتخدامهم للإنترنـت ناتجـة عـن العوامـل الديموجرافيـة (الجنس، السـن، المستوى التعليمي، نوع الإعاقة). r- توجد علاقة ارتباط ذات دلالـة إحصـائية بين العوامل الدافعيـة منمنلـة في الدوافع النفعيـة (الفائدة المتحققة)، الدوافع الطقوسية (المتعـة المتحققة) وكثافة استخدام ذوي الاحتياجات الخاصة للإنترنت. ب- توجد علاقـة ارتبـاط ذات دلالـة إحصـائية بـين العوامـل المتعلقـة بالوسيلة الاتصـالية (سـهولة الاسـتخدام ، درجـة المصـداقية) وبـين كثافـة اسـتخدام ذوي الاحتياجات الخاصة للإنترنت.

\section{نوع الدراسة:}

تتتــى هـذه الدراسـة إلىى فئة الدراسـات الوصـفية ، والتهي يمكن مـن

خلالكهـا الوصـول إلـى معلومـات حـول أنمـاط اسـتخدامات ذوي الاحتياجـات الخاصة لشبكة الانترنت، والمتغيرات المرتبطة بطبيعة هذا الاستخدام.

منهج الاراسة:

تعتمد هذه الدراسـة على منهج المسـح بالعينة على عينـة ميدانية ممثلة لجمهور ذوي الاحتياجات الخاصة. 


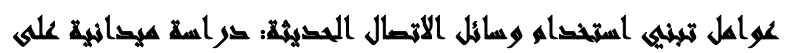

\section{عينة الدراسة:}

تمثلت عينة الدراسـة في عينة قوامها ـ ـ1 1 مفردة من المعاقين (سمعياً

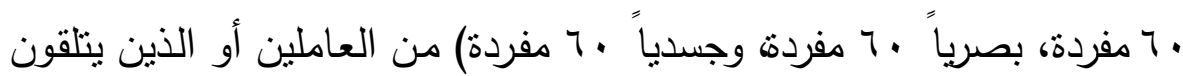
خدمات في مؤسسات الدولة (جمعيـة التأهيل الاجتمـاعي بحلوان، مؤسسـة يوم المستشفيات، الجمعيـة المصـرية لرعايـة وتأهيـل الصـم وضـعاف السـمع بمصر الجديدة، جمعيـة رسالة الخيريـة، جمعية امليون معاق، بعض شركات القطاع

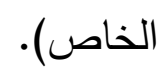

\section{أدواث جمع البياناث:}

قامت الباحثة بتصميم صحيفة الاستبيان لجمع البيانات من المعاقين بهمعياً وبصـرياً وجسدياً )، وقد استعانت الباحثة بمترجم بلغـة الإشـارة للتعبئة

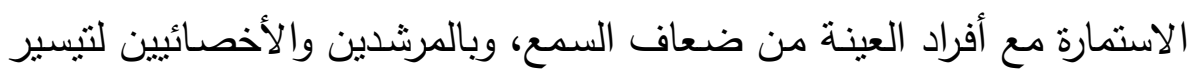

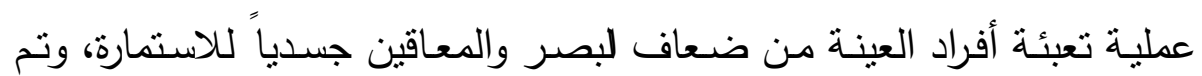
استيفاء الاستمارات باستخدام أسلوب المقابلة الثخصية. أولاً : تصميم استمارة الاستبيان:

استعانت الباحثة ببعض العبارات الواردة في الدراسات السابقة لصباغة عبارات مستقلة تقيس متغيرات الدراسـة، وتكونت استمارة الاستبيان من ثلاتثة مقاييس رئيسية ، تمثل اثثان منها العوامل المؤثرة في استخدامات أفراد العينة للإنترنت (العوامل المتعلقة بالمستخدم، العوامل المتعلقة بالوسيلة الاتصـالية)، إلى جانب مقياس لتحديد كثافة الاستخدام للوسيلة الإلكترونية. ثانياً : الأساليب الإحصائية المستخدمة:

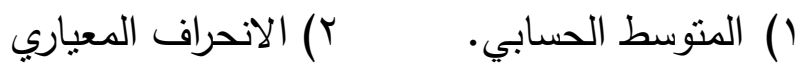




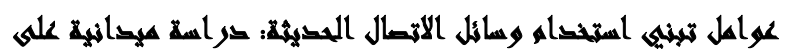

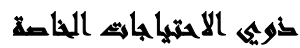

r) اختبار (ت) لتوضيح وجود أو عدم وجود فروق دالة بين متغيرين.

ع) اختبار ANOVA

0) معامل ارتباط التكرار لبيرسون.

ثالثاً : اختبار الصدق والثبات:

قامـت الباحثتة بعـرض اسـتمارة الاسـتبيان على عـدد مـن الأسـاتذة

المتخصصين في مجالات الإعـلام ومناهج البحث والتزبية الخاصـة، ثم قامت

بعدـل التعديلات اللازمـة في ضـوء ملاحظـاتهم، ولاختبـار ثبـات الاستمارة تم

إجراء اختبار قبلي على عينـة مصغرة مكونـة من · م مفردة من جمهور ذوي الاحنياجات الخاصة، ثم تم إعادة التطبيق بفاصل زمني أسبوعين من التطبيق الأول وبحساب معامل الارتباط بين التطبيقين بلغ ب 9, · وهو معامل يدل علي درجة ثبات عالية وعلى قابلية الاستمارة للتطبيق. نتائج الدراسة المبدانية وتفسيرها تعرض الجداول التالية توصيفاً لعينة الدراسة الميدانية:

جدول رقم (1)

يوضح توزيع عينة الدراسة وفقاً لنوع الإعاقة

\begin{tabular}{|c|c|c|}
\hline$\%$ & ك5 & نوع الإعاقة \\
\hline \% & 7. & معاقين جسدياً (ثلل أطفال ، بنز أطراف) \\
\hline$\%$ \%r,r & 7. & معاقين سمعياً (صم وضعاف سمع) \\
\hline$\% r r, r$ & 7. & معاقين بصرياً (مكفوفين وضعاف بصر) \\
\hline$\% 1 \ldots$ & 11. & الإجمـالي \\
\hline
\end{tabular}




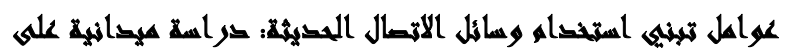

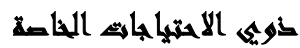

جدول رقم (r)

يوضح توزيع عينة الاراسة وفقا للجنس

\begin{tabular}{|c|c|c|}
\hline$\%$ & 5 & الجنس \\
\hline$\% \circ \vee, \wedge$ & $1 \cdot \varepsilon$ & ذكور \\
\hline$\% \leq r, r$ & VI & إنـاث \\
\hline$\% 1 \ldots$ & $1 \wedge$ & الإجمـالي \\
\hline
\end{tabular}

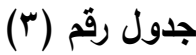

يوضح توزيع عينة الدراسة وفقا لفئات السن

\begin{tabular}{|c|c|c|}
\hline$\%$ & 5 & السن \\
\hline$\% 19$ & $r \varepsilon$ & أقل من ^1 سنة \\
\hline$\% 0 \cdot, 0$ & 91 & من ^| : ر سنة \\
\hline$\% r \cdot, 0$ & 00 & أكبر من Y r سنة \\
\hline$\% 1 \ldots$ & 11. & الإجمالي \\
\hline
\end{tabular}

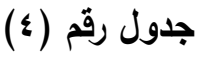

يوضح توزيع عينة الاراسة وفقا للمستوى التعليمى

\begin{tabular}{|c|c|c|}
\hline$\%$ & ك & المستوى التعليمي \\
\hline$\% 17,1$ & rq & منخفض (يقرأ ويكتب / تعليم أساسي) \\
\hline$\% r r, \wedge$ & 09 & متوسط ( تعليم ثانوي/ فني/ تجاري) \\
\hline$\% 01,1$ & ar & مرتفع ( فوق المتوسط/ تعليم جامعي / فوق الجامعي) \\
\hline$\% 1 \ldots$ & $1 \wedge$. & الإجمـالي \\
\hline
\end{tabular}




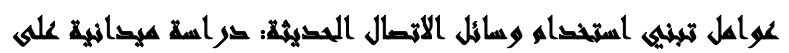

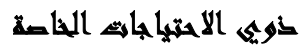

\section{النتائج الخاصة بتساؤلات الدراسة:}

يوضح الجدول التالي ما أسفرت عنه نتائج الدراسة الميدانية بثأن كثافة

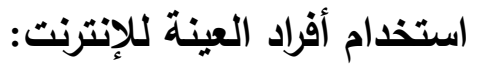

جدول رقم (•) - ج)

\begin{tabular}{|c|c|c|c|c|c|c|c|}
\hline \multirow{2}{*}{ الاستخدام } & \multicolumn{2}{|c|}{ أكثر من ؛ ساعات } & \multicolumn{2}{|c|}{ 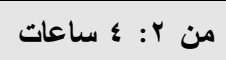 } & \multicolumn{2}{|c|}{ أقل من ساعة } & \multirow[t]{2}{*}{ المواقع الإكترونية } \\
\hline & $\%$ & ك & $\%$ & ك & $\%$ & ك & \\
\hline$\% 1, \wedge$ & $\% r \cdot, r$ & rv & $\%$ & 90 & $\% \leqslant r, r$ & $\vee \wedge$ & البريد الاكتروني (gmail,yahoo,Hotmail,...) \\
\hline$\%$ \%,० & $\% ฯ \vee, \wedge$ & irr & $\% \backslash \wedge, r$ & re & $\% 1 r, q$ & ro & مواقع التواصل الاجتماعي (facebook,twitter) \\
\hline$\% 1,0$ & $\% \vee, r r$ & ir & $\%$ \%ัa, \& & $v_{1}$ & $\% \circ r, r$ & 94 & الشبكات الإخبارية (الصحف والمجلات الاكترونية). \\
\hline$\% 1, \vee$ & $\%$ \%, v & ra & $\% r_{0,4}$ & $\leq 4$ & $\% \bullet r, \wedge$ & 90 & مواقع التسوق والثراء. \\
\hline$\% 1, r$ & $\% \varepsilon, \leqslant \leq$ & $\wedge$ & $\% 14,1$ & rq & $\% \vee ৭, \&$ & $1 \leqslant r$ & المدونات الاكترونية. \\
\hline$\% 1, \wedge$ & $\% \nmid \wedge, q$ & $r \varepsilon$ & $\% \leqslant r, \wedge$ & vv & $\%^{r \wedge, r}$ & 79 & مجموعات وغرف الحوار المباشر (الدردشة). \\
\hline$\%$ r, & $\%$ \%०, & $1 \varepsilon$ & \%rr,r & 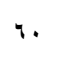 & $\%$ \%, 1 & 04 & محرك البحث جوجل. \\
\hline$\%$ r,r & $\% \leqslant 1, \vee$ & vo & $\%$ \% q, ६ & $v_{1}$ & $\% \backslash \wedge, q$ & $r \varepsilon$ & مواقع رفع وتحميل الملفات والبرامج. \\
\hline$\% r, l$ & $\% r_{\bullet, q}$ & $1 \varepsilon$ & \%rr,q & $\pi$ & $\%$ \%, , ฯ & $\infty$ & المواقع المتخصصة في ذوي الاحتياجات الخاصة. \\
\hline$\% 1,0$ & $\% 14,1$ & rq & $\% r$ & r & $\%$ \% & 110 & تليفزيون الإنترنت أو وراديو الإنترنت \\
\hline
\end{tabular}

\section{تشير بيانات الجدول السابق إلى ما يلى :}

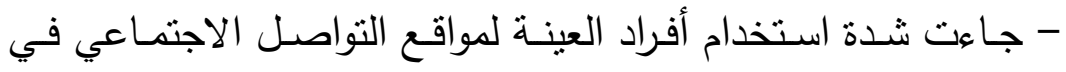

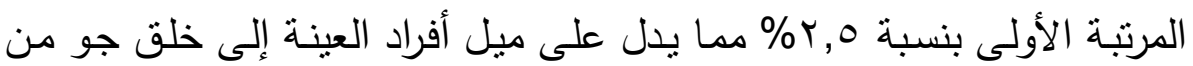

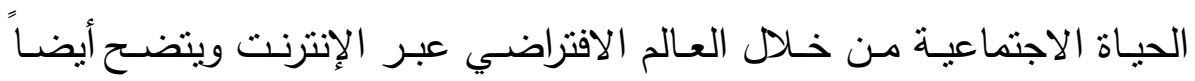

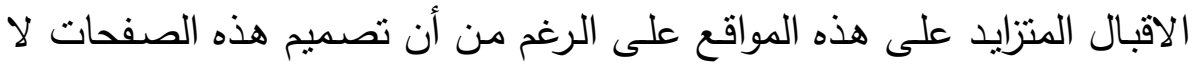

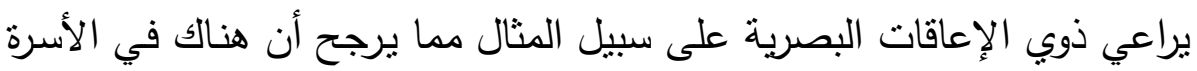




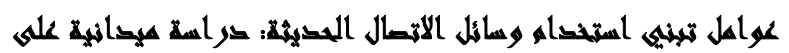

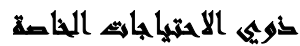

من يتولى مهمة مساعدتهم عند استخدامهم لمواقع التواصل الاجتماعي.

- جاءت شدة استخدام مواقع رفع وتحميل البرامج في الترتيب الثاني

حيث بلغت شدة الاستخدام Y, Y\%\%، ويعود ذلك إلى اهتمام أفراد العينة بتحميل البرامج التي تستخدم كتطبيقات هامـة في وسائل الاتصـال الحديثة (الإنترنت، الهواتف المحمولة) والمعينة لهم على عملية الاتصـال كبرامج قارئات الثاشـة للمعاقين بصرياً وتطبيقات تواصل المترجم الإرشادي للمعاقين سمعياً. ويوضح الجدول التالي ما أسفرت عنه نتائج الدراسة الميذانية بشأن تأثير استخدام العينة الإنترنت على استخدامهم للوسائل الأخرى: جدول رقم (7) - (7) - (ج)

\begin{tabular}{|c|c|c|}
\hline$\%$ & ك & تأثير استخدام الإنترنت على وسائل الإعلام الأخرى \\
\hline$\% \diamond ৭, \xi$ & $1 \cdot v$ & قللت الإنترنت من استخدامي لوسائل الاتصال الأخرى (تأثير سلبي) \\
\hline$\% r r, q$ & 11 & صبحت الإتترنت مكملاً لوسائل الاتصال الأخرى (تأثير محايد) \\
\hline$\%$ & . & زادت الإنترنت من استخدامي لوسائل الاتصال الأخرى (تأثير إيجابي) \\
\hline$\% \curlyvee, \vee$ & ir & أخرى تذكر ( بديلاً لي عن وسائل الاتصال الأخرى). \\
\hline$\% 1 \ldots$ & $1 \wedge$. & 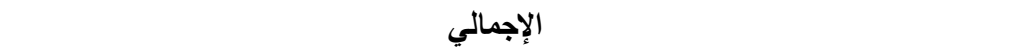 \\
\hline
\end{tabular}

تشير بيانات الجدول السابق إلى ما يلى :

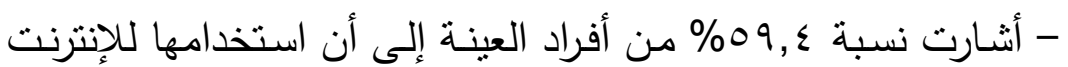

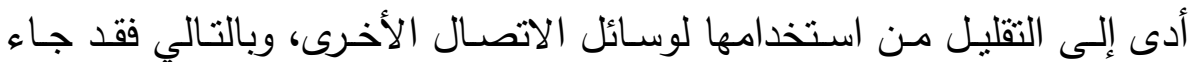
(التأثير السـلبي) على وسـائل الاتصـال الأخـرى في الترتيـب الأول، وأثنـارت

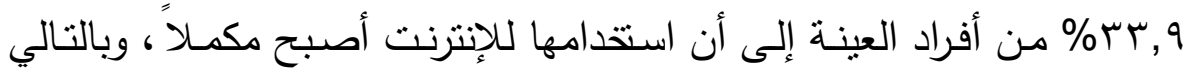
فقد جـاء (التأثير المحايـد) في الترتيب الثاني، فيمـا لـم تشـر العينـة إلى أن 


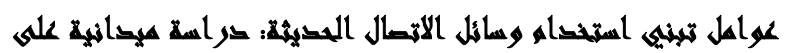

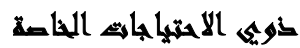

استخدامها للإنتزنت أدى إلى زيادة استخدامها للوسائل الأخرى، وعلى ذلك لم يحظ (التأثير الإيجابي) بـأي تقدير لـى عينـة البحث، وترى الباحثة أن هذه النتيجة نرجع إلى طبيعة الوسيلة الاتصالية التي تتضمن إمكانات جعلتها تحوي

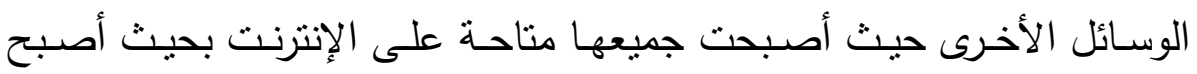
بإمكـان أبي شـخص، على صــحف العـالم، والاسـتماع للإذاعـة أو مشــاهدة التلفزيون أو الاتصال بأي شخص عن طريق الإنترنت مما قد يؤثز سلباً على الِى استخدام هذه الوسائل(9)، وتتقق هذه النتيجة مع دراسة "آلاء بنت سعود"( • ( ). ويوضتح الجدول التالي ما أسفرت عنه نتائج الاراسة الميدانية بشأن المضامين الإكترونية المفضلة لأفراد العينة: جدول رقم (v) جلاد

\begin{tabular}{|c|c|c|}
\hline$\%$ & ك5 & 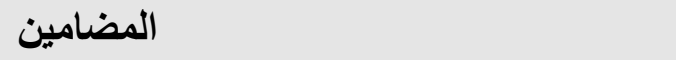 \\
\hline$\% \wedge r, r$ & $1 \leq \Lambda$ & المضامين المعلوماتية (الأخبار والمعلومات) \\
\hline$\% 7$. & $1 \cdot 1$ & المضامين التعليمية (مواد أكاديمية وبحثية) \\
\hline $0 \leqslant, \varepsilon$ & $9 \wedge$ & المضامين الترفيهية (الألعاب والمسابقات) \\
\hline$\% \leq r, r$ & $V 7$ & المضامين النقاشية (الحوارية) \\
\hline$\% 1 \ldots$ & 11. & الإجمالي \\
\hline
\end{tabular}

\section{تشير بيانات الجدول السابق إلى ما يلى :}

- تصـدرت (الأهـداف المعرفيـة) مـن اسـتخدام أفـراد العينـة للإنترنــت

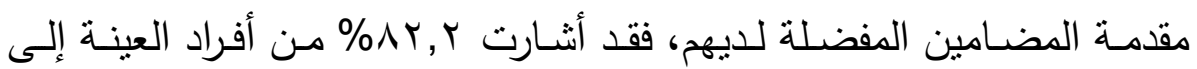

تفضيلها للمضامين المعلوماتية من أخبار ومعلومات حيث جاءت في الترتيب

الأول، وأثنارت نسبة ، ؟\% إلى تفضيلها للمضامين التعليمية من مواد أكاديمية 


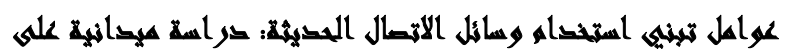

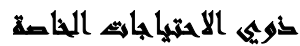

وبحثية حيث جاءت في التزتيب الثاني وتتبر هذه النتيجة إلى ميل أفراد ذوي الاحتياجـات الخاصــة إلىى اكتسـاب المعـارف والمعلومـات العامـة والأكاديميـة بأيسر الطرق خاصـة وأن هذه الفئات تعاني من المجهود الثـاق في الوصـول إلى مصادر المعلومات التقليدية من مكتبات ومراكز بحثية وغيرها من الأماكن التي تتيح خدمات معلوماتية، وإذا ما تمت الإثـارة إلى أن ما يزبد عن نصف عينة الدراسة بنسبة 1, 101\% هم من ذوي التعليم المرتفع، فإن ذلك يدعم نتيجة ميلهم إلى تقضيل المضامين المعلوماتية والأكاديمية.

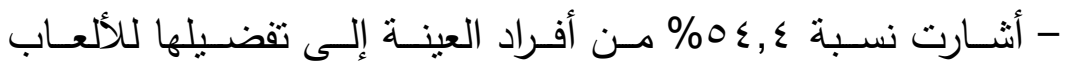
والمسـابقات المتاحـة على شـبكة الإنترنــت ، وبالتـالي فقـد جـاءت ( الأهـداف

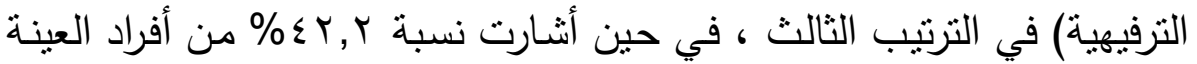
إلىى تفضـيلها للمضـامين النقاشـية والحواريـة، وبالتـالي فقد جـاءت (الأهـداف الوجدانية) في الترتيب الرابع. ويوضح الجدول التالي ما أسفرت عنه نتائج الدراسـة الميدانية بشأن أنماط استخدام أفراد العينة للإنترنت

جدول رقم (^)

\begin{tabular}{|c|c|c|}
\hline$\%$ & 5) & أنماط الاستخدام \\
\hline$\% । r, r$ & rr & القراءة فقط للنصوص والموضوعات والقضايا المتاحة (المستوى الأول) \\
\hline$\% 11,1$ & r. & القراءة والتحميل للموضوعات والقضايا على جهازي الخاص للاستفادة منها لاحقاً (المستوى الثاني) \\
\hline$\% r r, q$ & $\because$ & القراءة والمشاركة للموضوعات والقضايا على صفحتي الثخصية (المستوى الثالث) \\
\hline$\% \leq r, \wedge$ & VV & القراءة والمشاركة واضافة الرد على الموضوعات وعلى تعليقات الآخرين (المستوى الرايع) \\
\hline$\% 1 \ldots$ & $1 \wedge$. & 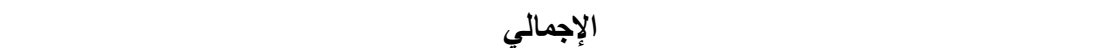 \\
\hline
\end{tabular}




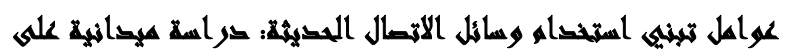

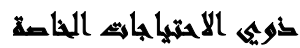

تثير بيانات الجدول السابق إلى ما يلى:

- أشارت ^, ^§\% من أفراد العينة إلى أنها تشتخدم (القراءة والمشاركة

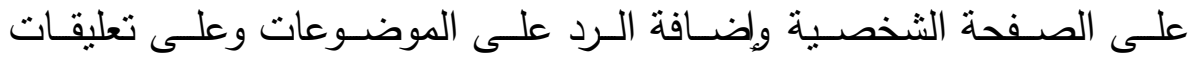

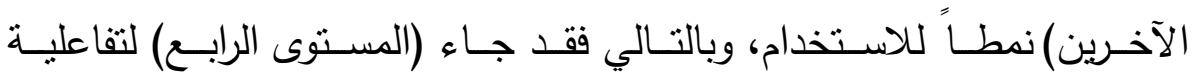
المستخدم مع المضامين الإكترونية في الترتيب الأول، وأثنارت نسبة و, وس\% من أفراد العينة إلى أنها تستخدم (القراءة والمشاركة للموضوعات والقضايا على

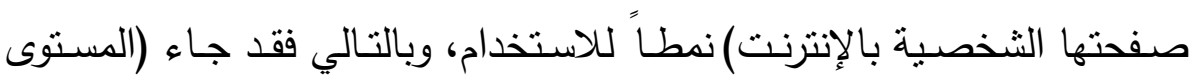
الثالث) في الترتيب الثاني، في حين أثنارت نسبة r, Y ( ) من أفراد العينة إلى أنهـا تسـتخدم (القـراءة فقط للنصـوص والموضـوعات والقضـايا المتاحـة على لـى الإنترنت)، وبالتالي فقد جاء (المستوى الأول) في الترتيب الثالث، فيما أثنارت نسبة |, 11\% من أفراد العينة إلى أنها تستخدم (القراءة والتحميل للموضوعات والقضايا على جهازها الخاص للاستفادة منها لاحقاً )نمطاً للاستخدام، وبالتالي فقد جـاء (المستوى الثاني) لتفاعليـة المستخدم مـع المضـامين الإلكترونيـة في

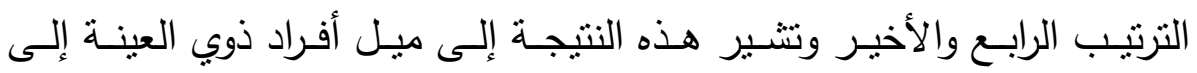
المشـاركة الفعالـة مـع المضـامين والمعلومـات والقضـايا المطروحسة على شـبكة الإنترنت سـواء مـن خـلال القراءة والمشـاركة والرد على الصفحة الشخصية أو وهئ مـن خـلال القـرارة والمشـاركة فقط على الصـفحة الشخصـية، وعـدم الاكتفـاء بالتفاعلية السلبية. 


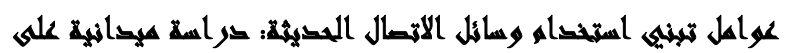

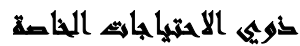

\section{* النتائج الخاصة بفروض الدراسة:}

1-توجد فروق ذات دلالة إحصائية في كثافة استخدام العينة

للإنترنت ناتجة عن الجنس (ذكور/إناث).

يوضح الجدول التالي الفروق بين الذكور والإناث في كثافة الاستخدام:

جدول رقم (9)

\begin{tabular}{|c|c|c|c|c|c|c|c|}
\hline الدلالة & درجة & قيمة ت & معامل الخطأ & الانحراف المعياري & المتوسط الحسابي & العدد & الجنس \\
\hline توجد فروق & $I V A$ & $r, \leqslant \leq q$ & $\cdot, \leqslant Y \wedge$ & $r, v r r$ & $1 V, 7 \leq$ & V & إناث \\
\hline عند 10 •,. & & & צ & $r, \nu \cdot \Lambda$ & $19, \cdot r$ & $1 \cdot \varepsilon$ & ذكور \\
\hline
\end{tabular}

تشير بيانات الجدول السابق إلى ما يلى :

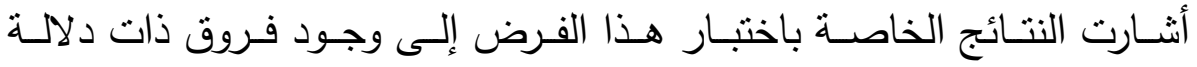
إحصائية بين الذكور والإناث في كثافة استخدامهم للمواقع الإلكترونية لصالح الذكور حيث بلغت قيمة (ت) المحسوبة 9 ؟ ؟ ب وهي قيمة دالة إحصائياً عند درجة حرية V V ا ومستوى دلالة 10 . ., ، ، وهذا يدل على أن الذكور من أفراد

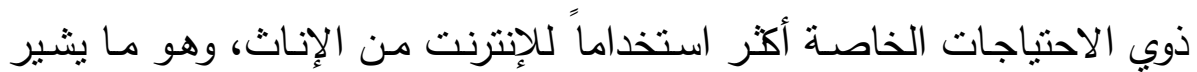
إلى عدم تكافؤ فرص الاستخدام بالنسبة للجنسين وهو مؤشر سـئ من حيث قدرة جميـع أفراد ذوي الاحتياجـات الخاصـة بمختلف الجنسـين على الوصـول

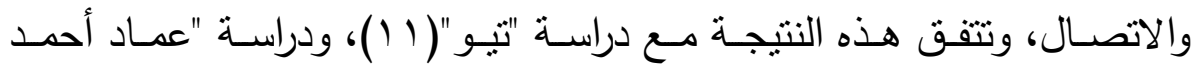
اسماعيل"( ( ) )، ودراسة "عبد العظيم دريفش"( ( ))، وتختلف مـع دراسـة "نصير صالح"( ؛ ( )، ودراسة "آلاء بنت سعود"(0) (10). 


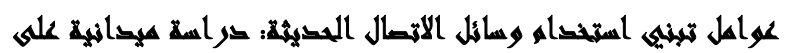

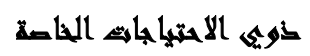

$$
\begin{aligned}
& \text { r - توجد فروق ذات دلالة إحصائية في كثافة استخدام العينة } \\
& \text { للإنترنت ناتجة عن الفئات العمرية. }
\end{aligned}
$$

\begin{tabular}{|c|c|c|c|c|c|}
\hline الدلالة & ف & متوسط المجموعات & درجة الحرية & مجموع المربعات & \\
\hline \multirow{3}{*}{ توجد فروق عن } & \multirow[t]{3}{*}{$r, \leq \leq 4$} & $\varepsilon \vee, \neg \wedge r$ & r & $90, r q \mu$ & بين المجموعات \\
\hline & & \multirow[t]{2}{*}{ 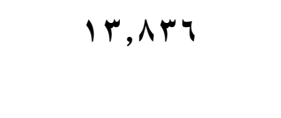 } & IVV & $r \leqslant \leqslant \wedge, 940$ & داخل المجموعات \\
\hline & & & 189 & $r \otimes \leq \varepsilon, r Y \wedge$ & الإجمالي \\
\hline
\end{tabular}

يوضح الجدول التالي الفروق بين الفئات العمرية في كثافة الاستخدام للإنترنت

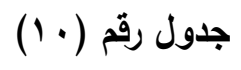

تشير بيانات الجدول السابق إلى ما يلى :

- توجد فروق ذات دلالـة إحصـائية بين الفئـات العمريـة

المختلفـة مـن أفراد العينـة في كثافـة اسـتخدامها للإنترنـت لصـالح

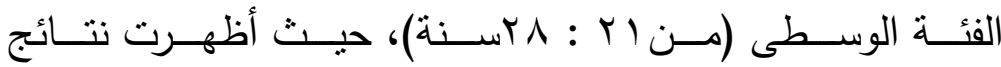

اختبار (ANOVA) وجود فروق فيما بين المجموعات حيث بلغت

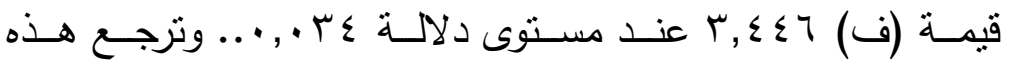

النتيجة إلى أن الثباب من أكثر فئات مستخدمي الإنترنت لتعدد

أغراض الاستخدام ما بين المعلوماتية والتسوق والبحث عن وظيفة

وتحميل البرامج، وعدم اقتصارها في اللعب والتسلية والدردشـة مثل

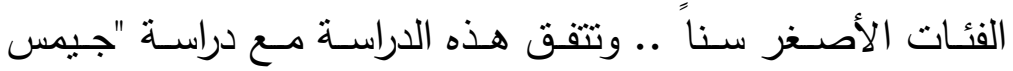

ليتيلفايلد"( 7 ( )، وتختلف مع دراسة " حمود وعبد الحافظ"( V ). 


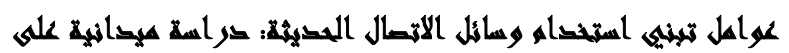

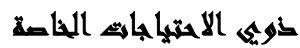

ب-توجد فروق في كثافة العينة للإنترنت ناتجة عن المستويات

التعليمية.

ويوضح الجدول التالي الفروق بين المستويات التعليمية في كثافة الاستخدام:

جدول رقم (11) - (11) - (2)

\begin{tabular}{|c|c|c|c|c|c|}
\hline الدلالة & ف & متوسط المجموعات & درجة الحرية & مجموع المربعات & \\
\hline توجد & \multirow{3}{*}{$\begin{array}{c}r, r Y \\
1\end{array}$} & MY,OIV & $r$ & $r 0, r \varepsilon$ & بين المجموعات \\
\hline فروق عند & & \multirow[t]{2}{*}{$1 \varepsilon, \ldots v$} & IVV & $r \leq \vee q, Y q \varepsilon$ & داخل المجموعات \\
\hline$\cdot, 1 \cdot 1$ & & & 189 & $r \otimes \leq \varepsilon, r, Y \wedge$ & الإجمالي \\
\hline
\end{tabular}

تشير بيانات الجدول السابق إلى ما يلى :

- توجـد فـروق ذات دلالــة إحصـائية بـين المسـتويات

التعليميـة المختلفـة مـن أفراد ذوي الاحتياجـات الخاصـة في كثافـة

استخدامها للمواقع الإلكترونيـة لصـالح ذوي التعليم المرتفع، حيث

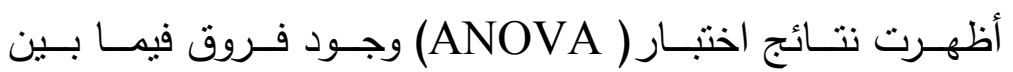

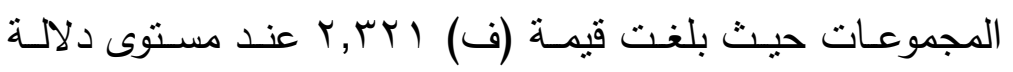

1 ( 1 . ، ، وقد ترجع هذه النتيجة إلى أن ارتفاع المستوى التعليمي

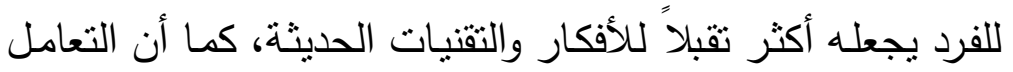

مع الإنترنت قد يتطلب من المستخدمين إتقان اللغة الإنجليزية وهو

ما يتوفر لدى ذوي التعليم المرتقع، وتختلف هذه النتيجة مع دراسـة

$$
\text { "على عقدة نجادات"(1 ( ) . }
$$




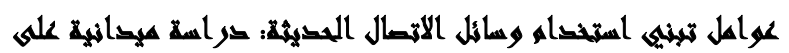

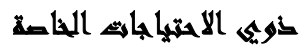

ع - توجد فروق ذات دلالة إحصائية في كثافة استخدام العينة

للإنترنت ناتجة عن نوع الإعاقة.

ويوضتح الجدول التالي الفروق بين الإعاقات في كثافة الاستخدام للإنترنت

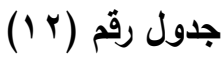

\begin{tabular}{|c|c|c|c|c|c|}
\hline الدلالة ل & ف & متوسط المجموعات & درجة الحرية & مجموع المربعات & \\
\hline \multirow{3}{*}{ فروق توجد } & \multirow[t]{3}{*}{ וr, } & $\varepsilon r, \varepsilon V r$ & r & $\wedge \neg, 9 \leq \varepsilon$ & بين المجموعات \\
\hline & & \multirow[t]{2}{*}{$I r, \wedge \wedge \varepsilon$} & IVV & $r \leq \Delta \vee, r \wedge r$ & داخل المجموعات \\
\hline & & & $1 v 9$ & $r \bullet \varepsilon \varepsilon, r$ ^ & الإجمالي \\
\hline
\end{tabular}

تثبير بيانات الجدول السابق إلى ما يلى :

- توجد فروق ذات دلالة إحصائية بين أنواع الإعاقات

المختلفة من أفراد ذوي الاحتياجات الخاصـة في كثافة استخدامها

للمواقع الإلكترونيـة لصـالح ذوي الإعاقـة البصرية، حيث أظهرت

نتائج اختبـار ( ANOVA) وجـود فـروق فيمـا بـين المجموعـات

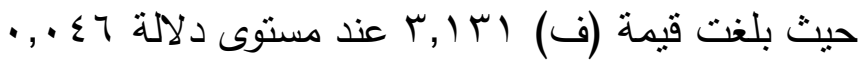

- ثاتبـا: نتائج اختبـار الفروض الخاصـة بالعلاقة بـين

العوامـل والمتغيـرات المختلفـة وكثافـة اسـتخدام ذوي الاحتباجـات

الخاصة للانترنت:

1 - توجد علاقة ارتباط ذات دلالة إحصائية بين العوامل الدافعية متمثلة في

الدوافع النفعية (الفائدة المتحققة) ، الدوافع الطقوسية (المتعة المتحققة)

لذوي الاحتياجات الخاصة وكثافة استخدامهم للإنترنت. 


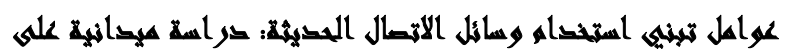

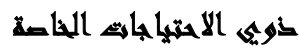

ويوضح الجدول التالي العلاقة بين الدوافع النفعية (الفائدة

المتحققة) لذوي الاحتياجات الخاصة وكثافة استخدامهم للإنترنت:

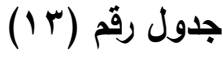

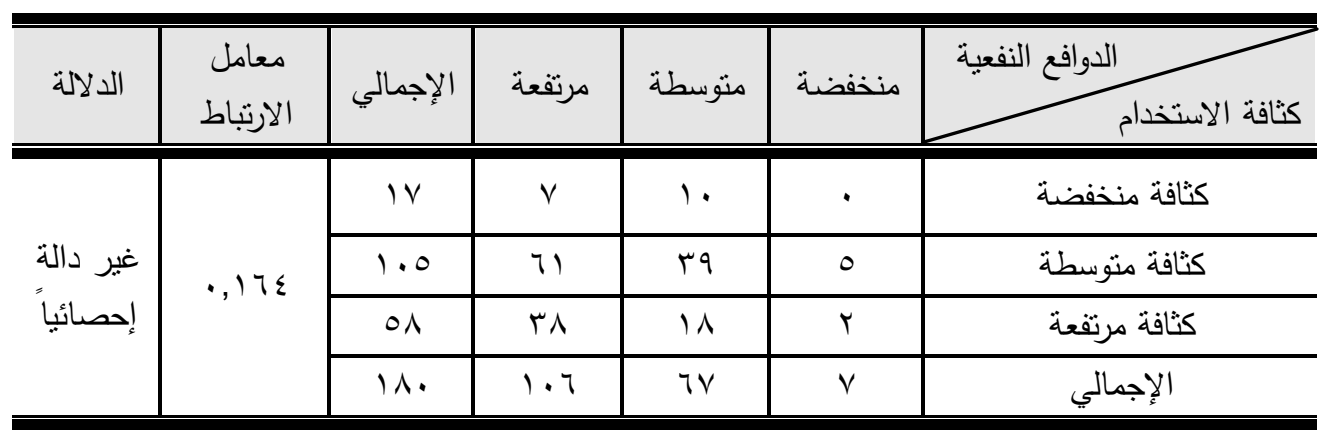

تشير بيانات الجدول السابق إلى ما يلى :

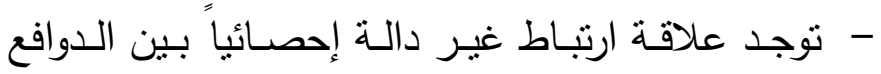

النفعيـة (الفائـدة المتحققـة) للعينــة وكثافــة اسـتخدامهم للمواقـع

الإلكترونيـة ، حيـث بلغـت قيمـة معامـل ارتبـاط التكـرار لبيرسـون

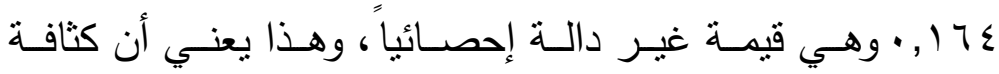

اسـتخدام أفـراد ذوبي الاحتياجـات الخاصـة للمواقـع الإلكترونيـة لا لا

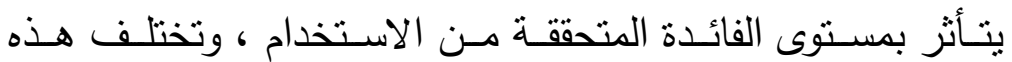
النتيجة مـع دراسـة "عبد الصـادق"(9 ( )، وتختلف مع دراسـة "رويتر

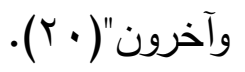

ويوضح الجدول التالي العلاقة بين الدوافع الطقوسية (المتعة المتحققة)

لذوي الاحتياجات الخاصة وكثافة استخدامهم للإنترنت: 


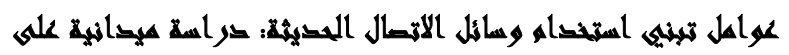

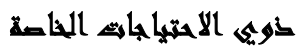

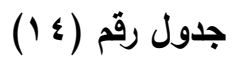

\begin{tabular}{|c|c|c|c|c|c|c|}
\hline الدلالة & الارتباط & الإجمالي & مرتفعة & متوسطة & منخفضة & \\
\hline \multirow{4}{*}{ مستوى دلالة ارتباط عند } & \multirow{4}{*}{ ع } & IV & ir & r & r & كثافة منخفضة \\
\hline & & 1.0 & vr & rt & . & كثافة منتوسة \\
\hline & & $0 \wedge$ & $r v$ & rV & $\varepsilon$ & كثافة مرتفعة \\
\hline & & 11. & 114 & 71 & V & الإجمالي \\
\hline
\end{tabular}

تثير بيانات الجدول السابق إلى ما يلى :

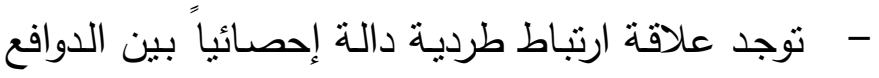

الطقوسية (المتعـة المتحققة) للعينـة مـن استخدام الإنترنت وكثافـة

استخدامهم لها، حيث بلغت قيمـة معامل ارتباط التكرار لبيرسون

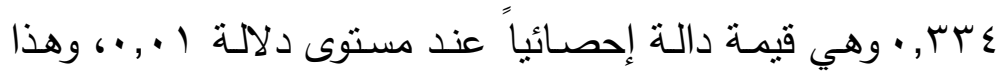

يعني أنه كلمـا زادت متعـة ذوبي الاحتياجات الخاصـة من استخدام

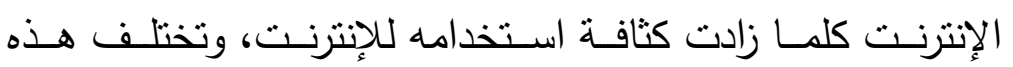

$$
\text { النتيجة مع دراسة "عماد أحمد إسماعيل"( الإن). }
$$

1- توجد علاقة ارتباط ذات دلالة إحصائية بين عوامل المتعلقة

بالوسيلة متمثلة (درجة المصداقية، سهولة الاستخدام) وبين

كثافة استخدام ذوي الاحتياجات الخاصة للإنترنت.

ويوضتح الجدول التالي العلاقة بين درجة مصداقية الإنترنت بالنسبة لذوي

الاحنياجات الخاصة وكثافة استخدامهم للمواقع الإلكترونية. 


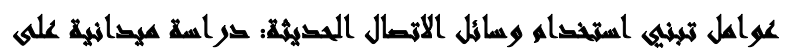

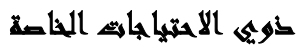

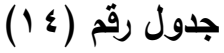

\begin{tabular}{|c|c|c|c|c|c|c|}
\hline الدلالة & الارتباط & الإجمالي & مرتفعة & منوسطة & منخفضة & \\
\hline \multirow{4}{*}{ غير دالةً } & \multirow{4}{*}{$\cdot, 194$} & IV & 7 & r & 9 & كثافة منخفضة \\
\hline & & 1.0 & r & r人 & rs & كثافة متوسطة \\
\hline & & $0 \wedge$ & r & Y) & $1 \leq$ & كثافة مرتفعة \\
\hline & & 11. & Tr & 71 & ov & الإجمالي \\
\hline
\end{tabular}

تشير بيانات الجدول السابق إلى ما يلى :

- توجد علاقة ارتباط غير دالة إحصائياً بين درجة مصداقية الإنترنت بالنسبة

لذوي الاحتياجات الخاصة وكثافة استخدامهم للمواقع الإكترونية ، حيث بلغت

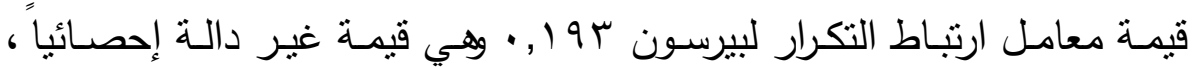

وهذا يعني أن كثافة استخدام أفراد ذوي الاحتياجات الخاصـة للمواقع الإكترونية

لا يتأثز بدرجة مصداقية الإنترنت كما يدركها أفراد ذوي الاحتياجات الخاصة.

ويوضتح الجدول التالي العلاقة بين سهولة الإنترنت بالنسبة لأفراد العينة

وكثافة استخدامهم للإنترنت.

جدول رقم ( 1 (1)

\begin{tabular}{|c|c|c|c|c|c|c|}
\hline الدلالة & الارتباط & الإجمالي & مرتفعة & متوسطة & منخفضة & ي السـولة \\
\hline \multirow{4}{*}{ | يوجد ارتباط } & \multirow{4}{*}{$\cdot, Y \circ \leqslant$} & 18 & 14 & $r$ & 1 & كثافة منخفضة \\
\hline & & 1.0 & 94 & IT & . & كثافة متوسطة \\
\hline & & 01 & rq & 17 & $r$ & كثافة مرتفعة \\
\hline & & 11. & $1 \leqslant \varepsilon$ & rt & $\varepsilon$ & الإجمالي \\
\hline
\end{tabular}




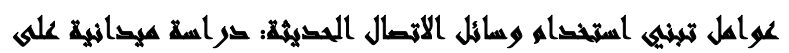

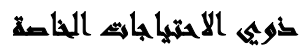

تشير بيانات الجدول السابق إلى ما يلى:

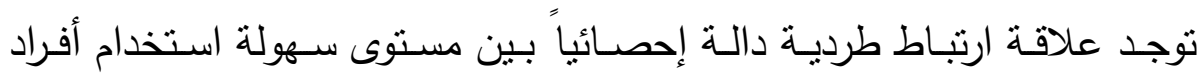
العينة للإنترنت وكثافة استخدامهم لها، حيث بلغت قيمة معامل ارتباط التكرار

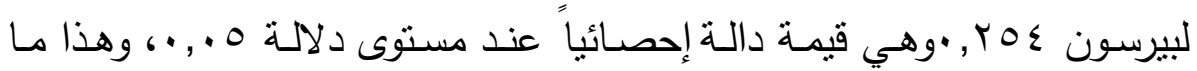

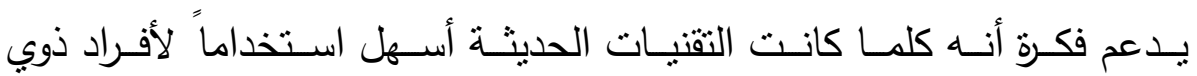
الاحتياجات الخاصة مع تخفيف العبء المادي في الحصول عليها ، كما ساعد وتتفق هذه النتيجة مع دراسة "باول"(r (Y). 


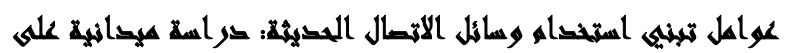

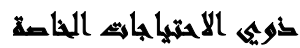

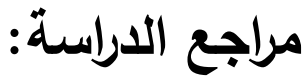

1-رأفت غنيم، استخدام تكنولوجيا الاتصالات والمعلومات لخدمة المعوقين، القاهرة، جامعة الدول العربية، إدارة التتمية والسياسات الاجتماعية، قطاع

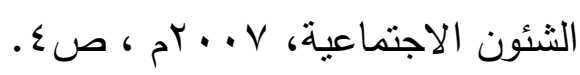

ץ- رادا حسين وآخرون، الاستخدام الأمثل لتكنولوجيا الاتصالات والمعلومات في توفير الخدمات للمعوقين، معهد تكنولوجيا المعلومات، وزارة الاتصالات وتكنولوجيا المعلومات، موقع أطفال الخليج ذوي الاحتياجات الخاصة، http://www.gulfkids.com/ar/book11-1543.htm

r- عبد الرحمن محمد سعيد، علاقة الثباب اليمني باتصالات الوسائط المتعددة: دراسة مسحية لعينة من المواقع الإكترونية للفضائيات العربية، المؤتمر الدولي السنوي الرابع عشر، الجمعية العربية الأمريكية لأساتذة الاتصال A AUSACE ع-نعايم سعد زغلول، الإعلام الحديث تكامل أم تتافس مع الإعلام التقليدى،

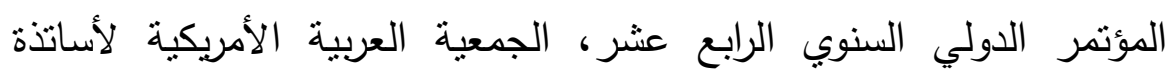

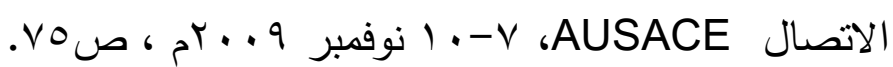

5- Robin P. Horton, Tamsin Buck, Patrick E. Waterson \& Chris W. Clegg, "Explaining intranet use with the technology acceptance model" , Journal of Information Technology, Vol. 16, Issue 4, pp. 237-249, 2001. 6-Teo , Thompsons . H , "Demographic and Motivation Variables associated with internet usage activiteies" , 


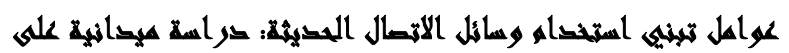

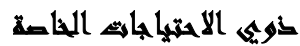

Internet Research Electronic Networking Applications and policy , Vol.11 , No. 2 , pp125-137, 2001.

7- June Lu, Chun-Sheng Yu , Chang Liu., James E. Yao, "Technology acceptance Model for wireless Internet" , internet Research Electronic Networking Application and Policy, Vol.13, No. 3 , PP. 206 - 222 , 2003.

^- عماد أحمد اسماعيل النونو، التسوق عبر الإنترنت.. دوافع التبني أو الرفض: دراسة ميدانية، رسالة دكتوراه غير منشورة، جامعة العالم الأمريكية، V +. r م. 9- إبراهيم بعزبز، وسائل الاتصال الجديدة وأثرها على ثقافة المستعملين، الملتقى الوطني: وسائل الإعلام والمجتمع، جامعة محمد خيض، بسكرة، الجزائر ،

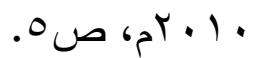

• 1-آلاء بنت سعود إبراهيم الزومان، تعرض الثباب السعودي للشبكات الاجتماعية: دراسة وصفية ميدانية على عينة من الطلاب والطالبات الجامعيين في مدينة الرياض، المنتدى السنوي السادس للجمعية السعودية للإعلام والاتصال: "الإعلام الجديد ..التحديات النظرية والتطبيقية"، جامعة

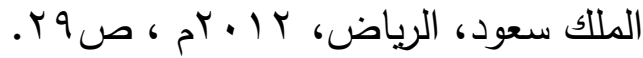
11-Teo, Thompsons . H. op.cit.

$$
\text { r ا - عماد أحمد اسماعيل، مرجع سابق ، صـ10. }
$$

ب ا - عبد العظيم دريفش جبار ، استخدام أسلوب تحليل المسار لنشخيص العوامل المؤثرة في نوايا العاملين بجامعة ذي قار للإتيان بسلوك استخدام الإنترنت، 


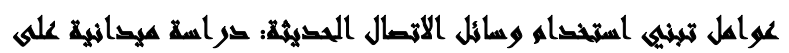

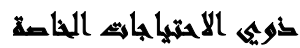

مجلة العلوم الاقتصادية والإدارية، جامعة بغداد، المجلدها، العددسه،

$\cdot r^{r} \cdot \cdot 9$

ء ا-نصير صالح بوعلي، استخدام الثباب الجامعي لوسائل الإعلام التقليدية والحديثة: دراسة على عينة من طلبة جامعة الثارقة، مجلة رؤى استراتيجية، ، V Vركز الإمارات للاراسات والبحوث الاستراتيجية، أبو ظبي، العدد

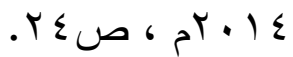

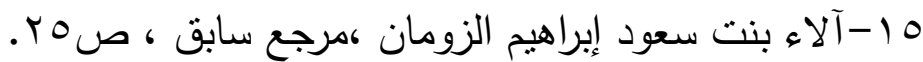

16- James E. Littlefield, Yeqing Bao \& Don L. Cook , "internet real estate information : are home Purchasers paying attention to it? " journal of consumer Marketing ,Vo1.17, No.7, pp 575-590, 2000.

IV المعاقين الإعلامية ودى إثباع وسائل الإعلام لها، الملتقى السابع للجمعية الخليجية للإعاقة: الإعلام والإعاقة علاقة تفاعلية ومسئولية متبادلة، الجمعية الخليجية للإعاقة بالتعاون مع المؤسسة الوطنية لخدمات المعاقين، البحرين،

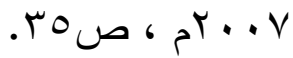
1 ا - علي عقله نجادات، استخدام المتزوجات العاملات في الجامعات الأردنية للفيسبوك والإشباعات المتحققة منه: دراسة مسحية على عينة من جامعة

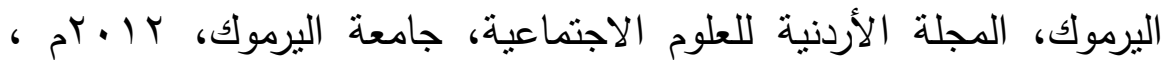
ص صדr. 


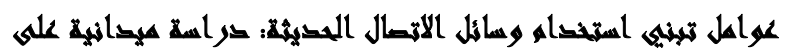

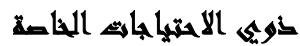

9 1 - عبد الصادق حسن عبد الصادق، دوافع استخدام الثباب الجامعي في

الجامعات البحرينية لإذاعات الإنترنت: دراسة ميدانية، مجلة رؤى استراتيجية،

مركز الإمارات للدراسات والبحوث الاستراتيجية، أبو ظبي، العددء،

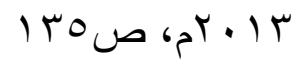

20- Ko de Ruyter, Martin Wetzels and Mirella Kleijnen ,

"Customer adoption of e-service: an experimental study" , International journal of service Industry Management, vol.2, pp.184-207. Available at: file://C:/Users/te/Downloads/Documents/file2706.pdf ا Y-عماد أحمد إسماعيل ، مرجع سابق ، صو9 V.

22- Paul M.A. Baker ," Factors Influencing Adoption Of Wireless Technologies: Key Policy Issues, Barriers And Opportunities For People With Disabilities" , Information Technology and Disabilities Journal, Vol. 9 , No.2, 2003. 